\title{
Study on the gas movement in oxy-fuel combustion heating furnace
}

\author{
Yongfu Wua $\mathrm{Wuanglei}^{\mathrm{a}}$, Gao ${ }^{\mathrm{b}}$, Liangliang $\mathrm{Li}^{\mathrm{c}}$, Zhongxing Liu ${ }^{\mathrm{d}}$
}

School of Inner Mongolia university of Science and technology, Baotou 014010, China.

awyf07@imust.cn, b315292939@qq.com, c892793281@qq.com, dliuzx2@126.com

Key words: oxy-fuel combustion heating furnace; FDS; gas movement; correlation analysis

\begin{abstract}
In order to study the gas movement in oxy-fuel combustion heating furnace, the fire simulation software FDS (Fire Dynamics Simulator) is used to build the simplified model of oxy-fuel combustion heating furnace and carry on the correlation analysis of simulation parameters and mesh number which impact the calculation accuracy. Based on the above correlation analysis, the numerical calculation of the gas movement in the cold state oxy-fuel combustion heating furnace at different nozzle speeds is carried out, and the calculated results are compared with the experimental results measured by the hot wire anemometer to verify the correctness of the simulation. The results suggest that the maximum reflux region increases with the increase of the air velocity and has a certain time delay under the condition of experiment speed, which provides a reference for the ignition delay of the thermal state oxy-fuel combustion heating furnace.
\end{abstract}

\section{Introduction}

In recent years, energy and environmental problems have affected the daily life of human beings. More than $70 \%$ of China's energy use comes from the burning process of fossil fuels [1]. The burning of fossil fuels produces a lot of waste gas and waste residue, which not only pollute the environment, cause the greenhouse effect and hazy weather, but also endanger human health, affect the survival and development of human beings. Therefore, it is of great significance to improve the combustion process for energy conversion and environmental protection.

In many combustion processes heating can be enhanced by replacing some or all of the air with pure oxygen. The combustion with oxygen is called oxy-fuel combustion [2]. The general benefits of oxy-fuel combustion include its high combustion efficiency, high melting capacity, low exhaust gas volumes, low fuel consumption and low NOx emission [3]. When the oxidants all use oxygen, combustion system due to no $\mathrm{N}_{2}$ involvement, theory does not produce any nitrogen oxides. As a result, the emission of the pollutant gas is largely reduced, the heating of nitrogen in gas and flue gas is reduced, and the thermal efficiency of the system is improved to meet the requirements of high efficiency and low pollution [4]. Thus, the research of oxy-fuel combustion technology is of great significance for energy-saving and emission-reduction.

Different levels of oxygen combustion technology are studied at home and abroad. Narayana et al. [5] operated their oxy-fuel furnace on flameless mode for heat release rate of $26 \mathrm{~kW} / \mathrm{m} 3$. The oxygen is sprayed into the furnace through a slight asymmetric injection nozzle at the speed of sonic and the resulting flame is weak bluish in color with little soot and acetylene formation. It is shown by Kim et al. [6] that FGR technology is quite effective for reducing the NO emission in the oxy-fuel combustion heating furnace. The experimental data show that when the $0.03 \mathrm{MW}$ oxy-fuel combustion heating furnace operates under the condition of 40\% FGR ratio, the NO emission level is below $30 \mathrm{ppm}$ and the reduction rate of NO emission is about $93 \%$. When the $0.2 \mathrm{MW}$ oxy-fuel 
combustion heating furnace operates under the condition of $40 \%$ FGR ratio, the NO emission level is lower than $150 \mathrm{ppm}$ and the reduction rate of NO is about $85 \%$.Kee R.J. et al. study on the equilibrium between $\mathrm{NO}$ emission and nitrogen percentage in an oxidizer [7]. The results show that when the nitrogen percentage in the oxidizer reaches approximately $30 \%$, the NO emission level reaches a peak value, while the percentage of nitrogen in the oxidizer does not exist or more than $80 \%$, the NO emission level is almost zero. The results of this study have a great guiding role in the design and application of oxy-fuel combustion. In China, Pengfei Li et al. [8] study on MILD oxy-fuel combustion in a $20 \mathrm{~kW}$ laboratory combustion furnace. Experimental and simulation results show that under the condition of pure oxygen as oxidizer, MILD combustion state can also be achieved. Huazhong University of Science and Technology [9] has focused on integrating the advantages of MILD combustion and oxy-fuel combustion to study the combustion technology of "zero emission" of pulverized coal based on capturing and storaging $\mathrm{CO} 2$ from exhaust gas. After repeated studies, they found that the combustion characteristics of this system is very stable, the burnout degree is quite high and it can solve the problem that the actual combustion stability is poor and combustion is not complete and so on. As MILD oxy-fuel combustion technology is becoming more and more mature, the technology has been applied to the glass melting furnace and iron and steel smelting in China, however, the application of this technology in industrial heating furnace is very little. This is the place to study in detail in this paper.

With the development of computational fluid dynamics (CFD), more and more people use the CFD method to simulate the flow of turbulent combustion. Due to the calculation method has the advantages of low cost, computing period is short, the applicability of multi scale problems is good and it is very suitable for the study of burning or combustion gas flow problem [10]. In this paper, the numerical simulation method is used to simulate the gas movement in the furnace under the cold state. The simulation results are compared with the experimental results to verify the reliability of the CFD method.

\section{The model construction of the oxy-fuel combustion heating furnace}

FDS is developed by the NIST (national institute of standards and technology) and it is the computational fluid dynamics software who takes the fluid movement in the fire as the main research object [11]. When the software is carried out to simulate the combustion flow, the governing equations include: continuity equation, momentum conservation equation, stress tensor equation, energy conservation equation and ideal gas equation. The above 5 equations have the same characteristics of nonlinearity, coupling property, formal similarity and sealing property. And these common characteristics constitute the basic equation of describing the gas flow and combustion in the oxy-fuel combustion furnace [12-13].In this paper, the designed industrial combustion furnace is used as the model, FDS software is used to carry out modeling and numerical calculation and the gas movement in the oxy-fuel combustion furnace under the condition of cold state is simulated.

2.1. Mathematical model. The governing equations are as follows:

Continuity equation: $\frac{\partial \rho}{\partial t}+\nabla \cdot \rho \vec{u}=0$

Momentum conservation equation: $\frac{\partial(\rho \vec{u})}{\partial t}+\nabla \cdot \rho \vec{u} \vec{u}+\nabla p=\rho \vec{g}+f+\nabla \cdot \tau_{i j}$ 
Stress tensor equation: $\tau_{i j}=\mu\left(2 S_{i j}-\frac{2}{3} \delta_{i j}(\nabla \cdot \vec{u})\right)$

Energy conservation equation: $\frac{\partial(\rho h)}{\partial t}+\nabla \cdot \rho \vec{u} h=\frac{D p}{D t}+q^{\prime \prime \prime}-q_{b}^{\prime \prime}+\varepsilon$

Ideal gas equation: $P=\frac{\rho R T}{\bar{W}}$

\subsection{Physical model.}

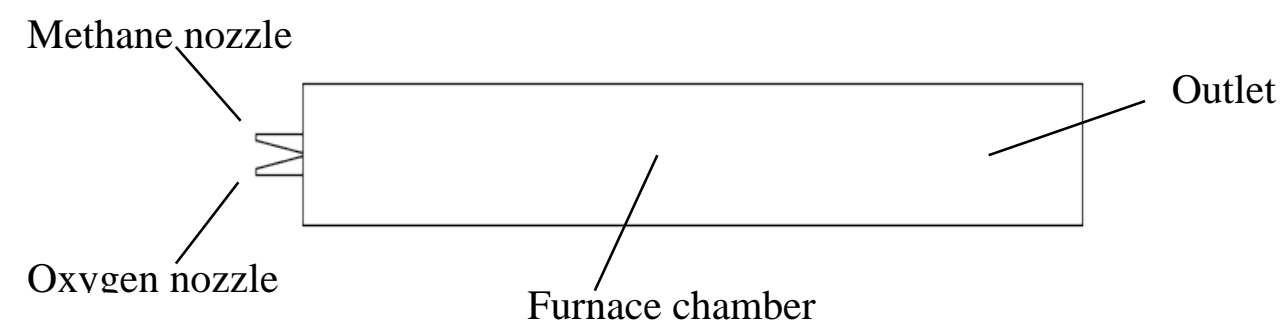

Fig. 1 Schematic diagram of oxy-fuel heating furnace physical model

As shown in Figure 1, there are three main parts of the oxy-fuel combustion heating furnace, the nozzle, the furnace chamber and the outlet. The upper nozzle is provided with methane and the oxygen supply is in the lower nozzle. The design of combustion furnace is as follows: length = $2000 \mathrm{~mm}$, width $=200 \mathrm{~mm}$, height $=200 \mathrm{~mm}$, nozzle angle $=8^{\circ}$, two nozzle spacing $=10 \mathrm{~mm}$. The methane and oxygen are injected into the furnace chamber at a certain speed, and both of them increase the disturbance in the furnace to form a reflux and diffuse to the whole furnace. In the end, the state of MILD combustion is achieved in the furnace chamber and the exhaust gas is discharged from the outlet. The calculation areas include nozzle interior and the whole furnace, which mainly analyses the gas movement in them.

\section{Grid independence test}

In order to ensure the accuracy of calculation and save the calculation time, the grid independence is needed to be tested. In this paper, we analyze the four kinds of Grid: $300 * 30 * 30,400 * 40 * 40,500 * 50 * 50,600 * 60 * 60$, and the results are shown in table 1 . The position of the point velocity which is analyzed is $(28,100,100)$ from the nozzle side. Regard the simulation results obtained when the grid number is $400 * 40 * 40$ as benchmark, other simulation results under other grid numbers are compared with it. As can be seen from table 1, with the increase of the grid numbers, the simulation results tend to be stable. Compared with the simulation results of $400 * 40 * 40$, the increase of the grid numbers can not obviously change the results of calculation. Considering the calculation time, the calculation accuracy and the performance of computer and other factors, the grid of $400 * 40 * 40$ is used in the end for simulation and calculation.

Table 1 Point velocity and ratio of different grid numbers

\begin{tabular}{ccccc}
\hline Grid number & $300 * 30 * 30$ & $400 * 40 * 40$ & $500 * 50 * 50$ & $600 * 60 * 60$ \\
\hline Point velocity $(\mathrm{m} / \mathrm{s})$ & 2.27 & 2.62 & 2.53 & 2.71 \\
Ratio & $86.6 \%$ & $100 \%$ & $96.6 \%$ & $103 \%$ \\
\hline
\end{tabular}




\section{Cold state experiment of the oxy-fuel combustion heating furnace}

\subsection{Experimental set up of cold state.}

Figure 2 and figure 3 are the experimental apparatus and principle diagram for the experimental platform. Each part in figure 3 represents: 1- carrier frame, 2- organic glass furnace, 3-gas nozzle (upper: methane, lower: oxygen), 4- tracer particle loader, 5- piezometer, 6- thermal gas flow meters.
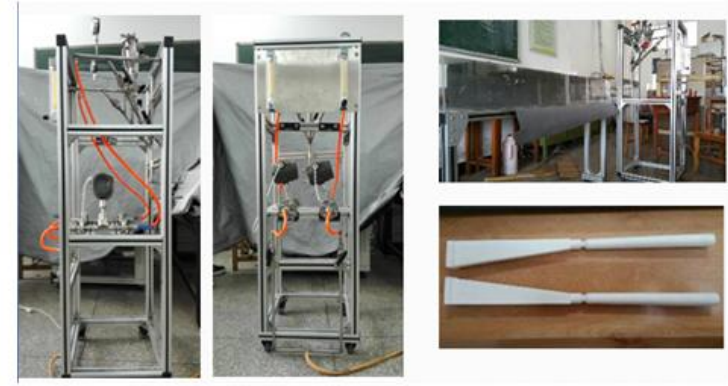

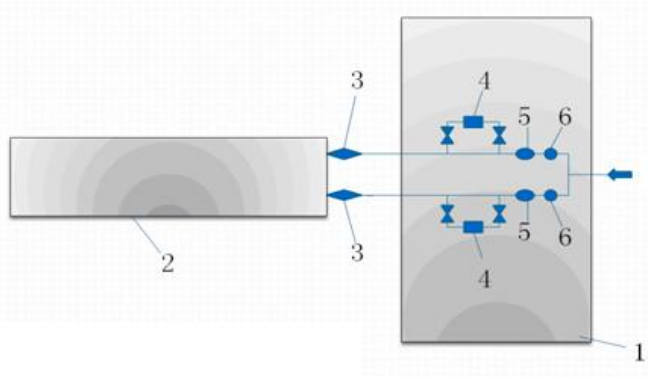

Fig.2 Diagram for experimental apparatus in cold state Fig.3 Principle diagram in cold state

\subsection{Experiment of hot wire anemometer in cold state.}

By using a set of experimental platform, the experiment of hot wire anemometer is carried out. Experimental scheme is as follows: select the 8 degrees angle nozzle, jet methane and oxygen at the velocity of $40 \mathrm{~m} / \mathrm{s}$ and $80 \mathrm{~m} / \mathrm{s}$ respectively, fix the hot wire anemometer on the three-dimensional experiment frame, and measure the wind velocity in different horizontal and vertical positions of the central cross-section. Selecting the horizontal positions of $X=28 \mathrm{~cm}, X=32 \mathrm{~cm}, X=36 \mathrm{~cm}$ and vertical positions of $Y=3.7 \mathrm{~cm}, Y=6.9 \mathrm{~cm}, Y=10.1 \mathrm{~cm}, Y=13.3 \mathrm{~cm}, Y=16.5 \mathrm{~cm}$. Figure 4 to 6 is the velocity change diagram of different height in the central cross-section based on the experimental results.

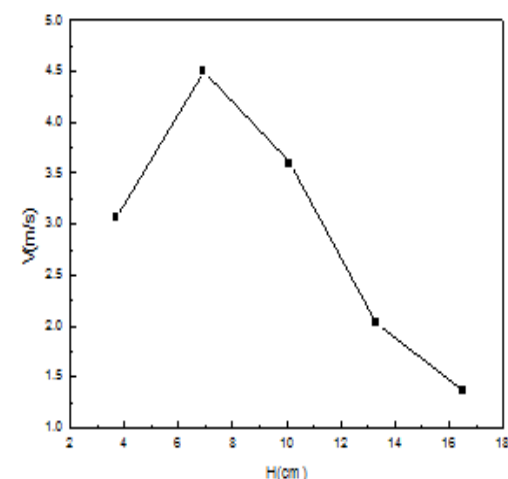

Fig.4 Velocity change diagram in the vertical direction when $\mathrm{X}=28 \mathrm{~cm}$

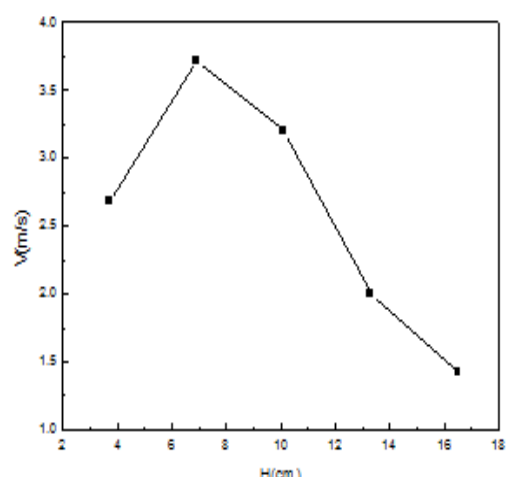

Fig.5 Velocity change diagram in the vertical direction when $\mathrm{X}=32 \mathrm{~cm}$

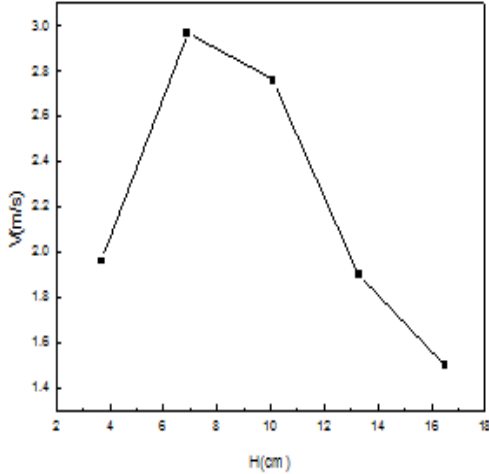

Fig.6 Velocity change diagram in the vertical direction when $\mathrm{X}=36 \mathrm{~cm}$

As we can see from figure 4 to 6 , the measuring point velocity decreases with the increase of $\mathrm{X}$ distance. In the vertical direction, the velocity of the measuring point near the nozzle is always higher than that of the measuring point on both sides of the nozzle, the velocity of the measuring point around the oxygen nozzle is larger than that of the measuring point around the methane nozzle, and the velocity in the furnace will reach the maximum at $Y=7 \mathrm{~cm}$. 


\section{Numerical simulation of gas flow in the oxy-fuel combustion heating furnace under cold state}

\subsection{Comparison of experiment and numerical simulation of different position velocity.}

The experiment of hot wire anemometer has been carried out for the velocity of the central cross-section at different $x$ positions changed with the change of the vertical direction. This part is mainly used to compare the experimental results with the simulation results to verify the accuracy of simulation results. Figure 7 to 9 is the experiment and simulation comparison diagram of velocity with the change of the vertical direction on the central section $X=28 \mathrm{~cm}, X=32 \mathrm{~cm}, X=36 \mathrm{~cm}$ when the jet velocity of oxygen and methane were $80 \mathrm{~m} / \mathrm{s}$ and $40 \mathrm{~m} / \mathrm{s}$, respectively.

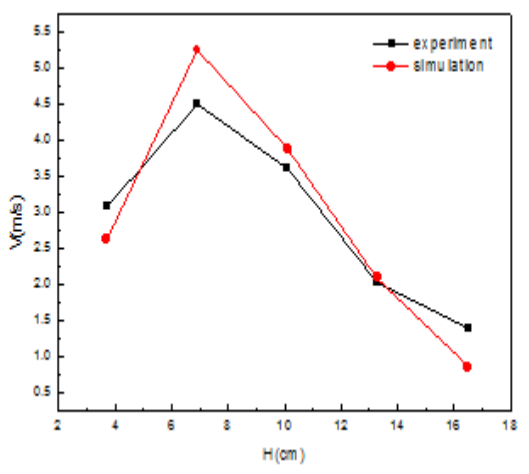

Fig.7 Experiment and simulation comparison diagram of velocity with the change of the vertical direction on central section $\mathrm{x}=28 \mathrm{~cm}$

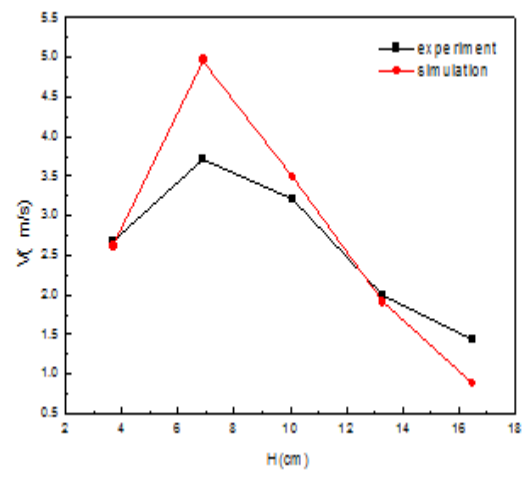

Fig.8 Experiment and simulation comparison diagram of velocity with the change of the vertical direction on central section $\mathrm{x}=32 \mathrm{~cm}$

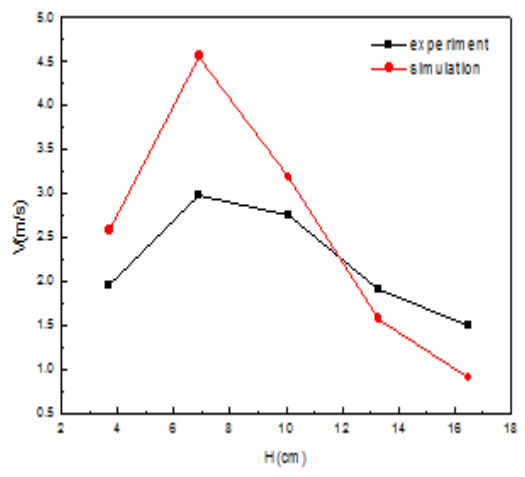

Fig.9 Experiment and simulation comparison diagram of velocity with the change of the vertical direction on central section $\mathrm{x}=36 \mathrm{~cm}$

Comparing figure 7 to 9 can be found that the experimental and simulation of the gas velocity change is basically the same, the gas velocity reached the peak value when $Y=7 \mathrm{~cm}$. The main reason is that the position $\mathrm{Y}=7 \mathrm{~cm}$ is located near the lower nozzle-oxygen nozzle, and the speed of it is relatively high, so the maximum gas velocity appears there. Analysis the change trend, it can be seen from figure 7 to 9 that: either experiments or simulation, the trend of gas velocity fluctuation in the vertical direction is shown as getting bigger from bottom to top, and then decreases after the maximum value appears at $Y=7 \mathrm{~cm}$. The main reason is that the upper and lower ends of the furnace body are far away from the nozzles, the gas velocity will have a certain loss when spread from the nozzle to the two ends, so the gas velocity is relatively lower at both ends; the middle area of the two nozzles is a combination of two gases, so the velocity of this area is between the two nozzles; and the gas velocity at the two ends of the nozzle is mainly affected by the gas velocity of the nozzle which is close to them. To sum up, the minimum gas velocity appears on the upper ends of the furnace. Comparing the three figures, it can be found that the experiment and simulation results are in better agreement when $X=28 \mathrm{~cm}$ than $X=32 \mathrm{~cm}$ or $X=36 \mathrm{~cm}$, and the results when $X=32 \mathrm{~cm}$ is better than that of $X=36 \mathrm{~cm}$. The reason is that the larger the $X$, the more close to the furnace outlet, and the more obvious effects from the furnace outlet (The simulation is carried out in a closed area, but the hot wire anemometer needs to be placed in the experimental furnace, thus, the furnace outlet is needed in practical). Summary of the three above images, it is not difficult to find: whether the speed or the speed change trend, the anastomosis of experiment and simulation is very high, so as to ensure the accuracy of the simulation results. 


\subsection{Numerical simulation of gas movement in combustion furnace with different nozzle gas velocity.}

This section uses FDS technology to simulate the gas movement in the cold state when the oxygen and methane jet velocity are respectively $(20 \mathrm{~m} / \mathrm{s}, 10 \mathrm{~m} / \mathrm{s}),(50 \mathrm{~m} / \mathrm{s}, 25 \mathrm{~m} / \mathrm{s}),(100 \mathrm{~m} / \mathrm{s}, 50 \mathrm{~m} / \mathrm{s})$. Figure 10 to 12 is the nephogram of the gas flow field in the furnace under three kinds of nozzle gas velocity obtained by the reflux length.

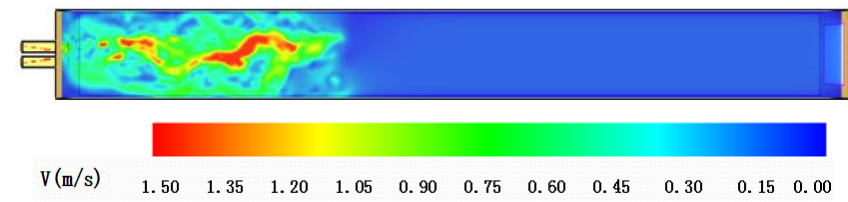

Fig.10 Gas flow field nephogram of oxygen and methane nozzle with the speed of $(20 \mathrm{~m} / \mathrm{s}, 10 \mathrm{~m} / \mathrm{s})$

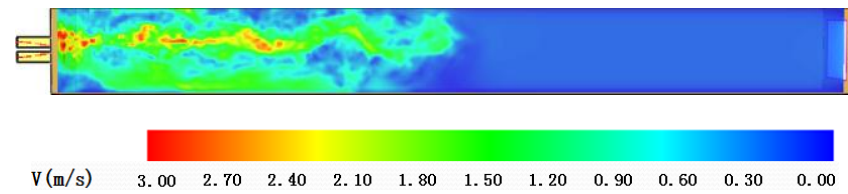

Fig. 11 Gas flow field nephogram of oxygen and methane nozzle with the speed of $(50 \mathrm{~m} / \mathrm{s}, 25 \mathrm{~m} / \mathrm{s})$

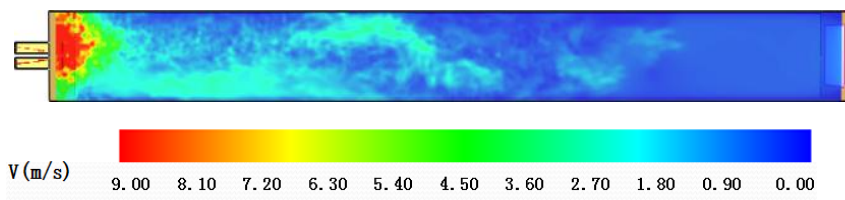

Fig.12 Gas flow field nephogram of oxygen and methane nozzle with the speed of $(100 \mathrm{~m} / \mathrm{s}, 50 \mathrm{~m} / \mathrm{s})$

The simulation results in Figure 10 to 12 show that the maximum reflux length in the combustion furnace is $0.62 \mathrm{~m}$ when the oxygen and methane jet velocity is $(20 \mathrm{~m} / \mathrm{s}, 10 \mathrm{~m} / \mathrm{s})$; the maximum reflux length in the combustion furnace is $0.78 \mathrm{~m}$ when the oxygen and methane jet velocity is $(50 \mathrm{~m} / \mathrm{s}, 25 \mathrm{~m} / \mathrm{s})$; and $0.97 \mathrm{~m}$ when the jet velocity is $(100 \mathrm{~m} / \mathrm{s}, 50 \mathrm{~m} / \mathrm{s})$. The analysis results show that the greater the nozzle velocity, the longer the maximum reflux length of the gas in the furnace, and greater the reflux area. With the increase of the nozzle velocity, the speed required to form the maximum reflux length is also increased (The formation velocity of the three cases were $0.403 \mathrm{~m} / \mathrm{s}, 0.561 \mathrm{~m} / \mathrm{s}, 0.683 \mathrm{~m} / \mathrm{s}$, respectively). Comparing the above figures, it can be found that there are big differences between the gas movement velocity in the furnace and the gas velocity injected into the furnace. This is because the gas in the furnace has a different degree of spreading in all directions. Therefore, the velocity of gas movement in the furnace is relatively low.

\section{Conclusion}

(1) For the grid independence test, it is concluded that the most reasonable number of internal grid should be set to $400 * 40 * 40$ under this furnace model. This will not only save the time of the simulation calculation, but also ensure the accuracy of the calculation results.

(2) The comparison between the experimental results and the simulation results proves the accuracy of the results of the FDS software, which provides a basis for the future simulation of the FDS software.

(3) Under the experimental condition of cold state, the bigger the jet velocity, the larger the reflux zone, the shorter the mixing time of the gas in the furnace, the more favorable to the formation of efficient and clean MILD combustion. This is a guide for the choice of gas injection velocity, the control of the gas spread time and the determination of the velocity of the gas in the furnace. And 
these results provide references for the ignition delay of the thermal state oxy-fuel combustion heating furnace.

\section{Acknowledgements}

This work was financially supported by the National Natural Science Foundation of China (51464014), the Major State Basic Research Development Program of China.

\section{References}

[1] IPCC. Climate Change 2007: impacts, adaptation and vulnerability: contribution of Working Group II to the fourth assessment report of the Intergovernmental Panel on Climate Change. Cambridge Univ Press. 2007.

[2] Krishnamurthy N, Paul P J, Blasiak W. Studies on low-intensity oxy-fuel burner. Proc Combust Inst, 2009, 32(2): 3139-3146.

[3] C.E. Baukal, Oxygen Enhance Combustion, CRC Press, 1998.

[4] R Eichler. Recent Developments in Oxy-fuel Technology for Heating Furnaces[J]. Proc. IFRF's 25th ToTeM, Stockholm, Sweden, 2003: 2 7.

[5] H.K. Kim, Y. Kim, S.M. Lee, K.Y. Ahn, Combust. Inst. 31 (2007) 3377-3384.

[6] R.J. Kee, F.M. Rupley, J.A. Miller, Sandia National Laboratories Report SAND89-8009, 1990.

[7] Pengfei Li, Bassam B. Dally, Jianchun Mi, et al. MILD Oxy-Combustion of Gaseous Fuels in a Laboratory-Scale Furnace[J]. Combustion and Flame, 2013, 160 (5): 933-946.

[8] Xianjun Xing, Qizhao Lin Department of Thermal Science and Energy Engineering, University of Science and Technology of China, Hefei 230026

[9] Yuda Huang, Xia Wei, Zhaoguo Sun, et al. Numerical simulation research of turbulent combustion flow field based on parallel computing. Science Technology and Engineering, 2012, 12(17): 4192-4196.

[10] Zhe Xin, Shunxi Wang, Feng Yun, et al. Numerical analysis on spreading laws of grassland fire based on fire dynamics simulator(FDS). Transactions of the Chinese Society of Agricultural Engineering,2013,29(11):156-163.

[11] Jun Liu, Min Liu, Huiqiang Zhi, et al. FDS fire dynamics simulator basic theory and application tips[J]. Safety,2006(1):6-13.

[12] LI Zai-zhen. Numerical analysis about the Shangjie highway of tunnel fire based on FDS[D]. Xi An:2011. 